\title{
Small Business Use of Electronic Networks
}

\author{
Addressing the needs of Australian small businesswomen
}

\author{
LEANNE WOOD \\ Southern Cross University, Lismore, Australialm.wood@qut.edu.au
}

\begin{abstract}
Electronic networking can be an effective way of meeting the needs of small businesswomen. While networking is considered to be a key strategy for business development, it is critical for women, who face structural disadvantages that limit their ability to exploit business opportunities. The Internet has the potential to address such needs. This paper suggests that the potential of electronic networking does not lie in its ability to replace existing physical networks. Rather, it exists in the capacity of electronic networking to meet the needs of small businesswomen by supplementing 'real world' connections in a way that increases their diversity, scope and business value.
\end{abstract}

\section{INTRODUCTION}

Networks are key tools for business owners attempting to make a place for themselves in a competitive marketplace. Since most small business owners have specific knowledge in a limited number of the areas in which management decisions need to be made, it will often be necessary for them to seek assistance from others. The degree to which they can access this help is critical since it is the means by which they obtain the resources they need [10]. For many women small business owners, however, the benefits of networking are constrained by structural disadvantages, such as the need to manage both work and care giver roles, that affect their ability to exploit business opportunities as effectively as men.

This paper reports on ongoing qualitative research that explores the ways in which Australian small businesswomen are exploiting the possibilities of Internet technology to overcome these structural constraints. The research thus far indicates that electronic networking can be an effective way of 
meeting the specific needs of small businesswomen - not by replacing existing 'real-world' networks, but by supplementing them in a way that increases their diversity, scope and business value.

\section{BARRIERS TO NETWORKING}

'Real-world' networking is frequently identified as a critical strategy for small business owners who want to advance their businesses. For the third of small business owners in Australia who are women, however, the benefits of networking are less easily accessed because of structural disadvantages that affect their ability to exploit business opportunities [8]. Women play the sole or leading role in running Australian small businesses in 13\% of cases; and share the leading role in another $19 \%$ [16]. The use of this figure is not intended to discount the business contributions or difficulties of women who do not have a leading role in their business partnership. Key life activities such as marriage and family, participation in the workplace and organized social life may be sources of barriers that limit the reach and diversity of women's networks [1]. Surveys of Australian small businesswomen suggest that the group is dominated by married women in their thirties to forties [16, 2]. It is women in this group who are most likely responsible for balancing ongoing family and work responsibilities. Such obligations are more likely to increase women's separation from business opportunities; restrict opportunities for furthering workplace-based skills; and limit the scope, location, time and energy available for business activity, and therefore business growth.

Networking poses additional difficulties for small businesswomen in rural contexts. In Australia, significant economic, social and environmental challenges have faced rural communities in recent years, and it is becoming increasingly common for women to work a triple shift of family, farm and paid employment [11]. Together, time and energy constraints, long distances and physical barriers may limit opportunities for rural small businesswomen to join networking groups or attend institutionally-based courses [15].

\section{NATURE OF SMALL BUSINESSWOMEN'S NETWORKS}

Previous studies have found the key difference between the networks of male and female business owners to be in their composition. Women's active networks have a high proportion of kin and close friends compared to 
men's networks, which tend to be dominated by business and male friends who typically have greater wealth and access to finance [3]. The dense, highly interconnected networks typical of women business owners require considerable time and emotional investment to maintain, and are a less likely source of new ideas and contacts because many of the individuals move in the same social circles. In contrast, the broader reach of men's informal networks provides greater opportunity to come across new and diverse information.

Thus, if there is business advantage in having many diverse information sources through a broad range of contacts, then it may be necessary for women to develop other strategies for gaining information. This appears to be a key driver for the emergence of women's business networking groups. Women's business networks are a means of linking women with other women to expand contacts, pass on information, provide successful role models, and generate solutions to problems. They formalise the opportunities for gaining diverse linkages.

At the same time, appropriate business networks respect the multiple roles and associated time poverty which shape the working lives of many small businesswomen. Women want access to business networks that are informal, flexible [5], and focused on professional development [12]. Social support is also considered to be a valued characteristic of women's business networks. The results of Smeltzer and Fann's [13] qualitative research indicate that small businesswomen seek social support as much as instrumental information through their external networks, and early feedback from this more recent Australian research indicates a similar focus.

\section{SMALL BUSINESS ELECTRONIC NETWORKING}

Small businesses in general face considerable challenges in the current economic climate. Increasing numbers of small businesses are responding to these pressures by including Internet connectivity among their strategies to increase competitiveness. The Internet provides opportunity to share information and experiences in addition to, and instead of, using more traditional methods of communication.

Electronic networks appear to be a particularly appropriate medium for women business owners. Women appear to be largely excluded from the informal, strong-tie networks to which male business owners have access, and so must meet their needs through formal weak tie networks that facilitate diverse contacts from different social arenas. Weak ties link individuals who possess different knowledge and information. Thus, an electronic business network may encompass people from a range of different social and 
geographic networks, who share experiences, knowledge and abilities for the mutual benefit of their businesses. This is particularly critical for rural small businesswomen, whose access to diverse sources of information within their communities is limited, and who are likely to be restricted by cost, time and/or infrastructure constraints when seeking resources. In addition, electronic networks can serve social purposes. Through the sharing of information electronic networking fosters supportive interaction and facilitate relationshipbuilding. Significant possibilities exist, therefore, for electronic networking to address the specific social and informational needs of small businesswomen.

Such uses vary in their social impacts. Kiesler [7] notes that electronic communication can have both mundane and significant social effects. Some uses of the technology may be defined as primarily 'amplifying,' in that they enable people to do what they have done before, but faster, more accurately or more cheaply. Other uses represent a transformation in the ways people view their world, in their social roles and institutions, in the ways they work or the political and economic challenges they face. Sometimes the amplifying effect is obvious first, and transformatory effects become evident at a later time [7].

It is user behaviour that determines whether the technology is amplifying or transformatory, as people adapt the technology to the requirements of their daily lives and shape its uses and meanings. At the same time, however, studies have found that both individuals and organisations often discover strategic uses for electronic communication that they did not anticipate when they began using the technology [7].

Here those uses which are primarily amplifying are described but, more importantly, the uses which have the potential to be transformatory - to effect significant change in women's lives in some way are identified. The methodology chosen had to be capable of exploring accounts of participants' attitudes, motivations and behaviour as they redefine this particular technology and create a personal framework that makes sense of their experiences [6]. While quantitative surveys of small businesswomen to determine their net usage and attitudes towards technology are not uncommon [9], qualitative research that addresses these issues within the broader context of businesswomen's lives is scarce. This research has been based on semi-structured, in-depth interviews with Australian small businesswomen from a diversity of industry backgrounds, age groups, geographic locations and levels of Internet experience and usage.

A number of themes have emerged across the range of uses to which Internet technology is currently put by individual small businesswomen. The technology is used to sustain and expand the range of network contacts; to facilitate real-world activities; to seek out information and keep abreast of 
the latest research and information; to provide a means of social support; and to provide alternate ways of conducting business.

\subsection{Just a note to say hello: sustaining and expanding network contacts}

Electronic networking complements the 'real-world' business and social networks formed by small businesswomen by enabling them to build relationships that were founded by face-to-face contact, but require maintenance to continue to be beneficial. It keeps the channel open: "I can keep in touch and say ... Thinking about you... I've kept them aware that I'm here and ... that's very important [because] there might be opportunities in the future ... People know me personally so I don't need the hard sell, it's more reminding them that I'm still out there and when I might be available..."

Electronic contacts are especially beneficial for small businesswomen because of the particular nature of their networks. The networks of small businesswomen are characteristically dense and interconnected, and dominated by strong tie relationships that require time and effort to maintain. Electronic networking enables women to expand their range of contacts and to sustain existing ties without investing heavily in time and energy.

\subsection{Coffee at noon: facilitating real-world activities}

Electronic networks address the time poverty common to small businesswomen who juggle multiple roles. E-mail, in particular, is frequently a facilitator of real-world activities: "I think the electronic [network] facilitates you getting together ... You can make contact very easily: 'We'll get together and have a chat.' Otherwise you probably wouldn't do it." Electronic networks therefore can encourage pro-activity in network maintenance. A significant part of this role is the way in which it enables small businesswomen to seek advice quickly and informally from friends and associates: Such a resource is critical for small businesswomen, given the time poverty that can restrict their ability to take part in more formal networking activities.

\section{3 'Does anyone know?...': the Internet as a research tool}

Australian small businesswomen are beginning to embrace electronic networking for information seeking. Early feedback from this research indicates that time poverty is a key influence in determining how small 
businesswomen set about gathering information. Their use of Internet technologies - the Web, e-mail and even chat lines - tends to be focused and clearly targeted toward meeting specific needs.

Electronic networks provide a convenient, time-efficient way to link with others who share specific interests and knowledge. They can also be an effective way of connecting with women at different levels of seniority and power, in diverse geographic locations, and from varying social backgrounds, and thus may help members to increase the reach and diversity of their weak-tie business networks.

\subsection{Thinking about you: electronic networks as social support}

Another key feature of women's networks is social support. Isolation in a business sense can be an impediment in the suburbs as well as in the bush, particularly for those women in micro- or home businesses who work alone, and juggle care giver and business responsibilities. This function has particular relevance for small businesswomen in rural contexts, who may find the more limited range of physical networks available to them insufficient or inappropriate for their needs. The Rural Women and ICTs Research Team [11] identified social isolation as one of the greatest obstacles facing enterprising women in rural and remote Queensland, and noted the potential of e-mail for enabling business women in these areas to develop supportive networks as particularly significant. The online discussion group, 'welink', which emerged from the project, provides a forum for both rural and urban women to chat, to share information and to meet other women with similar needs, interests or experiences. It has become a strong source of social support for participants, including those with small business interests.

While electronic networking is used to complement and facilitate 'real world' networking activities it also has the potential to play a different role in the lives of women who face constraints in establishing or maintaining an active physical business network. The success of welink in providing a source of social support for women across geographic, sectoral and age boundaries, suggests that electronic networking has significant potential to enable small businesswomen, rural and urban, to make connections that may reduce feelings of isolation. 


\subsection{It's a long way to town: alternate ways of doing business}

Internet technologies provide opportunities for small businesses, significantly reducing geographical and temporal constraints and increasing the capabilities of small businesses relative to their size. Such qualities particularly benefit those whose business was previously inhibited by their geographical location or the other responsibilities. Electronic networks provide one woman, living forty miles from a small town on a road which is impassable in the wet and educating her two children at home, with a means by which she can continue her career as a freelance journalist. A rural author plans to use chat technology to do classroom visits around Australia; another regional businesswoman uses chat to inform and educate others about her products. E-commerce generally is gaining recognition as a valid option for people in the bush and, increasingly, for those who have other responsibilities. Such options can be seen to have direct and significant impact on the lives of the small businesswomen who adopt them - they are, in Kiesler's terms, transformatory uses of the technology.

\section{CONCLUSION}

While innovative uses of the technology for business purposes can readily be seen to have general transformatory effects, such outcomes are less obvious when considering more mundane uses. Some of purposes to which Internet technologies are being put by small businesswomen primarily amplifying uses, enabling them to do what they have done before more easily. This research suggests, however, that the familiarity of these everyday uses distracts from the evidence of more transformatory effects occurring.

Amplifying uses should not be seen as an isolated phenomenon, but as integrally linked with the other social interactions in women's lives. By viewing apparently mundane activities such as use of e-mail within the whole context of small businesswomen's lives, it becomes clear that they can transform the ways in which women organize their lives and responsibilities, by meeting their specific needs and addressing the constraints which inhibit their business progress. This research suggests, therefore, that the potential of electronic networking does not lie in its ability to replace existing physical networks. Rather, it exists in the capacity of electronic networking to meet the particular needs of small businesswomen by supplementing 'real world' connections in a way that increases their diversity, scope and business value; and thus influence 
the ways in which women approach and organize their working and personal lives.

\section{REFERENCES}

1. Aldrich, H. (1989). Networking Among Women Entrepreneurs. In Hagan, O., Rivchun, C., and Sexton, D., (Eds.). Women-Owned Businesses. pp.103-132 New York: Praeger.

2. Australian Bureau of Statistics. (1996). Australian Economic Indicators. Canberra: Australian Government Publishing Service.

3. Borzi, A.M. (1994). The Gender Finance Gap, cited in Flinders University of South Australia, School of Commerce (1995). Women in Small Business: A Review of Research Canberra: Department of Industry, Science and Tourism.

4. Burton, C. and Ryall, C. (Eds.). (1995). Enterprising Nation: Managing for Diversity, Industry Task Force on Leadership and Management Skills Canberra: AGPS.

5. Employment and Skills Formation Council (ESFC). (1994). Making it Work: Women and Small Business: Small Business Employment and Skills Supplementary Report, Canberra: Australian Government Publishing Service.

6. Hakim, C. (1987). Research Design: Strategies and Choices in the Design of Social Research. Contemporary Social Research 13, p. 26.

7. Kiesler, S. (Ed.). (1997). Culture of the Internet Mahwah, NJ: Lawrence Erlbaum Assoc.

8. Loscocco, K., Robinson, J., Hall, R. and Allen, J. (1991). Gender and Small Business Success: An Inquiry into Women's Relative Disadvantage, Social Forces 70 (1), 65-85.

9. National Foundation for Women Business Owners (NFWBO Press release) (10 Dec., 1994). Women Business Owners More Likely Than Other Businesses to Use Computer Technology in their Companies. http://bbai.onramp.net:80/nfwbo/rm013.htm

10. Reese, P.R. and Aldrich, H. (1991). Gender Differences In Entrepreneurial Networks. Paper prepared for the 1991 Southern Sociological Meetings.

11. Rural Women and ICTs Research Team (1999). The New Pioneers Brisbane: Communication Centre, Queensland University of Technology.

12. Small Business Development Corporation (WA). (November 1994). Women and Small Business in Regional Western Australia. Perth: SBDC (WA).

13. Smeltzer, L. and Fann, G. (1989). 'Gender Differences in External Networks of Small Business Owner/Managers' Journal of Small Business Management.

14. Wellman, B. and Gulia, M. (1996). Net Surfers Don't Ride Alone: Virtual Communities as Communities, www.acm.org/ ccp/references/wellman/wellman.html

15. Women in business breaking down barriers (1 Sept 1999) WordsWorth communicating (press release).

16. Yellow Pages. $(1994,1996)$. Small Business Index Special Report: Women in Business. 